\title{
Research Paper: Persian Overall Assessment of the Speaker's Experience of Stuttering for Adults: the Impact of Stuttering on the Persian-Speaking Adults Who Stutter
}

Fariba Yadegari ${ }^{1}$ (D), Tahereh Sima Shirazi ${ }^{1}$, Peter Howell ${ }^{2}$ (D), Reza Nilipour ${ }^{1}$ (D), Meysam Shafiei ${ }^{3}$, Bizhan Shafiei ${ }^{3}$ (D), Zahra Ilkhani ${ }^{3}$, Fatemeh Satarian $^{4}$, Narges Jafari ${ }^{1}$, Robert William Quesal ${ }^{5}$ D, J. Scott Yaruss ${ }^{6 *}$

1. Department of Speech Therapy, University of Social Welfare and Rehabilitation Sciences, Tehran, Iran.

2. Division of Psychology and Language Sciences, University College London, London's Global University, London, United Kingdom

3. Department of Speech Therapy, School of Rehabilitation Sciences, Isfahan University of Medical Sciences, Isfahan, Iran.

4. Department of Speech Therapy, School of Rehabilitation, Tehran University of Medical Sciences, Tehran, Iran.

5. Western Illinois University, Macomb, Illinois, United States.

6. Department of Communicative Sciences and Disorders, Michigan State University, East Lansing, Michigan, United States.

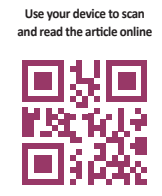

Citation: Yadegari F, Sima Shirazi T, Howell P, Nilipour R, Shafiei M, Shafiei B, et al. Persian Overall Assessment of the Speaker's Experience of Stuttering for Adults: the Impact of Stuttering on the Persian-Speaking Adults Who Stutter. Iranian Rehabilitation Journal. 2018; 16(2):131-138. http://dx.doi.org/10.32598/irj.16.2.131

doi : $:$ http://dx.doi.org/10.32598/irj.16.2.131

Article info:

Received: 25 Nov 2017

Accepted: 20 Mar 2018

\section{Keywords:}

Stuttering, Attitude, Quality of life, Persian

\begin{abstract}
A B STRACT
Objectives: This paper describes the validation process of the final form of the Persian version of the Overall Assessment of the Speaker's Experience of Stuttering for Adults (OASES-A-P). The impact of stuttering on the Persian-speaking people who stutter was compared to other languages.

Methods: This study with a cross-sectional design involved 92 Persian-speaking adults who stutter ( 24 females and 68 males; mean age $=20.05 \pm 4.85$ years). Face and content validity, internal consistency, test-retest reliability, and item analysis for discriminant validity were examined. The impact scores and impact ratings were calculated in total and for the sections separately.
\end{abstract}

Results: Cronbach's alpha and ICC proved to be high (0.98; 0.95, $\mathrm{P}<0.001$ respectively). Corrected item-total correlation revealed no negative score. Mean of total impact score was $2.56( \pm 0.67)$. Impact ratings for the total impact scores were as follows: mild $=8.7 \%$, mildto-moderate $=29.3 \%$, moderate $=43.5 \%$, moderate-to-severe $=15.2 \%$, and severe $=3.3 \%$. The impact of separate sections in a high to low order were reactions to stuttering, quality of life, general information, and communication in daily situations.

Discussion: The results of the current study offer a reliable and valid form of the OASES, which is applicable for Persian-speaking Iranian adults who stutter. The predominant impact rating of stuttering was shown to be mild-to-moderate and moderate.

\footnotetext{
* Corresponding Author:

J. Scott Yaruss, PhD

Address: Department of Communicative Sciences and Disorders, Michigan State University, East Lansing, Michigan, United States.

Tel: +1 (517) 8442406

E-mail:jsy@msu.edu
} 


\section{Introduction}

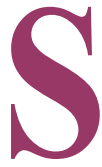

tuttering is a well-known fluency disorder that involves hesitations, repetitions, and prolongations; however, the experience of stuttering is not limited to such dysfluencies. Communication failures, listeners' reactions, and formed self-attitudes towards stuttering have great impacts on the Quality of Life (QOL) of People Who Stutter (PWS). In this regard, the phenomenon of living with stuttering in PWS can be studied through qualitative research $[1,2]$. Although the observable symptoms and severity of stuttering can be measured rather straightforwardly from a speech sample, it is difficult to measure a person's feeling about stuttering. These feelings are part of the so-called impact of a disease or a disorder on the individual's life. The results of the studies on the emotional-behavioral traits in PWS have been controversial with a continuum from no constitutional traits of nervousness [3] to the more prevalence of social phobia in the stuttering population [4-6]. On the other hand, the effect of stuttering on the lives of PWS cannot be underestimated; for example, the negative impact of stuttering on work life of PWS has been shown in a phenomenological analysis [7] and a QOL assessment [8]. The impact of stuttering on the lives of PWS has been studied in different areas including communicative attitudes [9-11], QOL [12, 13], nervousness [4, 14, 15], educational achievement [16], and attractiveness and romantic life [17]. Although studies regarding social anxiety reveal unconvincing effects, the overall conclusion of the above studies indicates a significant negative impact of stuttering on the lives of PWS.

In recent decades, measuring the impact of stuttering on the lives of PWS to aid decision making in clinical settings has become the target of several studies. In this regard, various tests and questionnaires have been developed (for a review see Yaruss and Quesal, 2006) [18]. Also, the assessment of health-related QOL of adults with chronic health conditions including stuttering has recently received much attention [19].

The Overall Assessment of the Speaker's Experience of Stuttering (OASES) protocol was designed to appraise four following components: the perceptions of fluency and speech behavior; the reactions to stuttering; the functional communication difficulties in key situations; and the consequences of stuttering on the lives of people who live with it, i.e., their QOL [18]. The OASES assessment tool was originally developed in English in three versions: For school-age children (ages 7-12 years), for teenagers (ages 13-17 years), and for adults (ages 18 years and above). Regardless of the age group, the OASES can evaluate the above-mentioned components. The questionnaire measures the phenomenon of stuttering as experienced by each individual speaker with a set of Likert scales. It contains items that reflect speakers' own perceptions about stuttering. Yaruss and Quesal (2004) explained how the development of the OASES protocol was based on the International Classification of Functioning, Disability, and Health [20].

Since its development [18]. , cross-cultural adaptations of the OASES have been done in some countries [2124]. Koedoot et al. (2011) investigated the psychometric properties of the Dutch version of the OASES. They examined the OASES on 138 PWS and evaluated the speeches of most of their participants on a Likert scale with 10 points. They also administered the severity of stuttering for another part of the subjects. The Dutch S-24 scale was completed by 32 of the participants. A good internal consistency, a moderate-to-high concurrent validity, and an appropriate construct validity were revealed through sections and subsections [22]. Blumgart et al. (2012) investigated normative data of OASES in the Australian population. They examined 200 Australian adults who stutter and found no significant relationships between OASES scores for sex and age. They compared Australian, USA and Dutch impact scores and impact ratings. The comparisons revealed that the three populations were comparable, with the moderate impact predominant in them [21]. Sakai et al. (2017) validated the Japanese version of the OASES (OASES-A-J) [24]. The results confirmed that OASES-A-J had an acceptable test-retest reliability ( $\mathrm{r}=0.81-0.95)$ and high internal consistency $(\alpha>0.80)$. The authors examined concurrent validity, which proved to be moderate-to-high (0.55-0.75); they also reported satisfactory construct validity. This was demonstrated through the correlation of internal consistency in each section and correlation among sections' impact scores. 'General Information,' 'Reactions to Stuttering' and 'QOL' sections showed a greater negative impact in Japanese adults. The authors suggested that OASES-A-J was a reliable and valid tool to test the impact of stuttering on Japanese adults who stutter. Sakai et al. (2017) suggested that OASES is long and tiresome for people who complete it, an issue which deserves further investigations.

In Iran, as in other countries and cultures, there is a need for an assessment tool for the impact of stuttering that can be completed by PWS who speak the language(s) of the country (the dominant language in Iran is Persian). Yet, a few studies in Iran have examined the various aspects of stuttering experience [25-28]. Communica- 
tion attitude test [9] was standardized in Iran on 48 children and adolescents who stutter in an age range of 8 to 15 years and 312 age-matched non-stuttering Persianspeaking students [28]. The study showed that students who stuttered had negative communication attitudes in contrast to non-stuttering students. Also, it revealed that older students with stuttering had more negative communication attitudes.

In general, there are not many studies examining the overall impact of stuttering on the adults (as the OASES does) in Iran. Thus, the present study aimed at investigating the impact of stuttering on the lives of Iranian PWS via the OASES-A-P. The questions of the study were as follows: 1) Is the OASES-A-P a valid questionnaire for face and content validity? 2) Is the OASES-A-P a reliable questionnaire regarding test-retest reliability and internal consistency? 3) Does item analysis reveal adequacy of the individual items? 4) What are the impacts of stuttering on the Persian-speaking PWS?

\section{Methods}

Ninety-two adults who stutter, including 24 females and 68 males, participated in this study with a cross-sectional design. Inclusion criteria were as follows: 1. Being stutterer; 2. Being adult; and 3. Being Persian-speaking. Exclusion criteria were: 1. Being neurologically impaired; 2. Being sensory impaired; 3 . Being illiterate; and 4. Being reluctant to cooperate. Participants were diagnosed as stutterer by an experienced Speech-Language Pathologist (SLP) through clinical examination. The participants ranged in age from 18 to 46 years (mean $=20.05$, $\mathrm{SD}=4.85$ ), and their years of education ranged from 12 to 18 years (mean=15.14, $\mathrm{SD}=2.04$ ). They were mostly recruited from an association for those who stutter; some were recruited from speech therapy clinics in Tehran. Of the 92 participants, 82 individuals provided information about prior treatment. Most had received speech therapy for stuttering during their lifetime $(n=75,91.5 \%)$; the duration of this therapy ranged from a minimum of 1 month to a maximum of 84 months (mean=21.41, $\mathrm{SD}=20.47$ ). Ethical considerations of the present research were approved by the review board of the University of Social Welfare and Rehabilitation Sciences. Participants were informed orally regarding the study. They were free to exit the research whenever they wished. The names and demographic information were kept confidential.

First, the OASES-A questionnaire was translated into Persian by two experienced SLPs. For assuring the accuracy of the items translated into Persian, an expert panel comprising a linguist, a native English-speaking stut- tering researcher, and two SLPs discussed the items in several sessions. Back translation was approved by the native English-speaking member of the panel. Hence, a typical forward and backward translation method was recruited for the questionnaire. This procedure led to the primary form of the OASES-A-P.

For a primary investigation of the face and content validity, the OASES-A-P was sent to 10 SLPs and psychologists. The questionnaire was amended according to their opinions and then was re-sent to 5 experts who had responded most completely in the first round of the reviews. As has been seen with other OASES translation projects [21-24], there were several items that needed to be altered because of cultural differences between Western countries and Iran, though an attempt was made to modify the questions as little as possible. Accordingly, a few items were manipulated to make the questionnaire congruent with Iranian culture.

The resulting form was investigated as mentioned in a preliminary validation study [29]. In that primary study, Shafie et al. sent the draft to 10 PWS, and both face validity and internal consistency were evaluated. Later, 50 PWS completed the questionnaire, along with a Persian translation of the S-24 test for probing the concurrent validity. Nevertheless, the impact scores were not calculated, and the impact ratings were not estimated. Following the results of that preliminary study, it was revealed that the wordings of some of the anchors on the Likert scale of that draft of the OASES-A-P needed to be altered, so the wordings were slightly amended. In the present study, this revised form of the OASES-A-P was distributed to 92 adults who stutter.

Internal consistency for 4 sections and for total OASES-A-P was calculated. Test-retest reliability was determined based on repeated measurement of a sample of 56 individuals who stutter, and the ICC was calculated. An item-by-item Pearson correlation for test-retest reliability analysis was also calculated. Impact scores were computed for sections and for the total questionnaire. The impact scores were compared to that of the USA [18] and Japanese results [24]. The impact scores were calculated for subsections of OASES-A-P as well. Moreover, an item analysis was done to establish discriminant validity.

\section{Results}

Cronbach's alpha scores for different sections of the OASES-A-P were as follows: section $1=0.88$, section $2=0.94$, section $3=0.96$, and section $4=0.97$. Cronbach's alpha for total sections was 0.98 . 
The intraclass correlation coefficient for test-retest of section 1 was $0.81(\mathrm{P}<0.001)$, for section 2 was 0.88 $(\mathrm{P}<0.001)$, for section 3 was $0.91(\mathrm{P}<0.001)$, and for section 4 was $0.96(\mathrm{P}<0.001)$.

The intraclass correlation coefficient for test-retest of total OASES-A-P was $0.95(\mathrm{P}<0.001)$. Figure 1 depicts the scatter plot of correlation of test-retest of impact scores of total OASES-A-P.

Inter-item correlation was used to establish discriminant validity. Corrected item-total correlation revealed no negative scores. Three items showed low correlations with the total score, with non-significant p-values:

The first item was item of section $1 \mathrm{C} 10$, which is about the feelings of PWS regarding therapy centers and consultation clinics $(\mathrm{r}=0.165, \mathrm{P}=0.124)$.

The second item was item of section $1 \mathrm{C} 7$, which refers to the feelings of PWS about their recent therapy programs $(\mathrm{r}=0.181, \mathrm{P}=0.093)$.

The third item was item of section $1 \mathrm{~B} 3$, which is regarding the extent of awareness of PWS of their stuttering events $(r=0.201, \mathrm{P}=0.064)$.

An item-by-item Pearson correlation for test-retest reliability analysis revealed the highest correlations for items in section 3 D3 $(r=1, P<0.001)$, followed by the item of section $3 \mathrm{C} 2(\mathrm{r}=0.928, \mathrm{P}<0.001)$, and the lowest correlations were observed for items of section $1 \mathrm{C} 5$ $(\mathrm{r}=0.466, \mathrm{P}<0.001)$.

Ceiling and floor effects were examined based on the following definitions: A floor was defined as occurring if the mean minus standard deviation was less than 1 and $30 \%$ or more subjects answered " 1 " for any item.

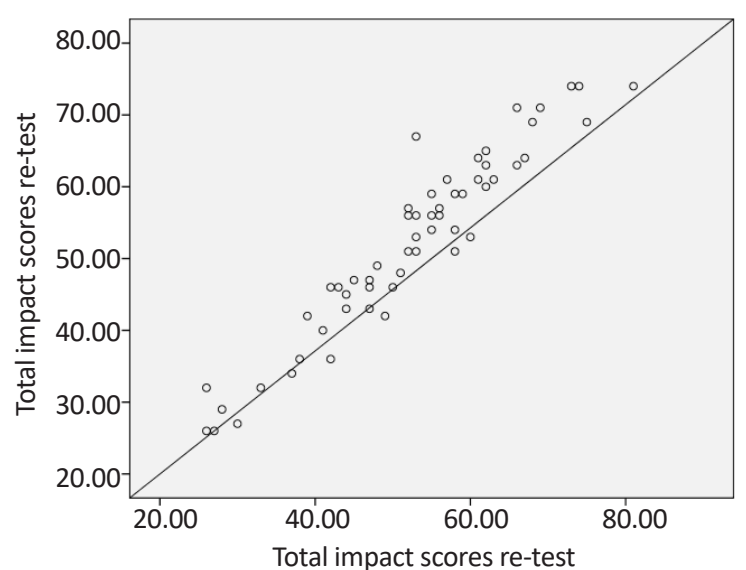

Iranian Rehabilitation Journal

Figure 1. Correlation of impact scores of total OASES-A-P in test and re-test

Likewise, a ceiling was defined as occurring if the mean minus standard deviation was greater than 1 and $30 \%$ or more subjects answered " 5 " for an item [24]. Floor effects were seen for 10 items. These items were as follows: section 2 A9, section 2 B2, section 3 A 5, section 3 $\mathrm{D} 2$, section $3 \mathrm{D} 3$, section $4 \mathrm{~B} 4$, section $4 \mathrm{C} 1$, section 4 $\mathrm{C} 2$, section $4 \mathrm{C} 4$, and section $4 \mathrm{H} 5$. No ceiling effects were found.

The following 7 items did not obtain a " 5 " score from any participants: Section1 A2; section $1 \mathrm{~B} 1$; section $1 \mathrm{~B} 2$; section $1 \mathrm{C} 2$; section $2 \mathrm{~B} 2$; section $3 \mathrm{D} 3$; and section 3 D4. There was no item without a "1" score. Table 1 depicts impact scores and impact ratings of the OASES-A-P obtained from 92 participants. Table 2 compares the impact scores and impact ratings of the OASES between Iran, Japan and the USA. Table 3 indicates the impact scores and impact ratings of four separated sections of the OASES-A-P.

Table 1. Impact scores and impact ratings of the OASES-A-P

\begin{tabular}{|c|c|c|c|c|c|c|c|}
\hline \multirow{2}{*}{\multicolumn{2}{|c|}{ Section }} & \multirow{2}{*}{$\begin{array}{c}\text { Impact } \\
\text { Scores } \\
\text { Mean(SD) }\end{array}$} & \multicolumn{5}{|c|}{ Impact Ratings (\%) } \\
\hline & & & Mild & Mild-to-Moderate & Moderate & $\begin{array}{c}\text { Moderate-to- } \\
\text { Severe }\end{array}$ & Severe \\
\hline Section 1 & $\begin{array}{l}\text { General infor- } \\
\text { mation }\end{array}$ & $2.50(0.51)$ & 12 & 53.3 & 30.4 & 4.3 & - \\
\hline Section 2 & $\begin{array}{l}\text { Reaction to stut- } \\
\text { tering }\end{array}$ & $2.65(0.69)$ & 5.4 & 23.9 & 39.1 & 26.1 & 5.4 \\
\hline Section 3 & $\begin{array}{l}\text { Communication } \\
\text { in daily situation }\end{array}$ & $2.44(0.80)$ & 17.4 & 25 & 32.6 & 19.6 & 5.4 \\
\hline Section 4 & Quality of life & $2.61(0.94)$ & 15.2 & 22.8 & 25 & 23.9 & 13 \\
\hline \multicolumn{2}{|c|}{ Total } & $2.56(0.67)$ & 8.7 & 29.3 & 43.5 & 15.2 & 3.3 \\
\hline
\end{tabular}


Table 2. The impact scores and impact ratings of the OASES between Iran, Japan and the USA

\begin{tabular}{|c|c|c|c|c|c|c|c|}
\hline \multirow{2}{*}{\multicolumn{2}{|c|}{ Section }} & \multicolumn{2}{|c|}{$\operatorname{Iran}(n=92)$} & \multicolumn{2}{|c|}{ Japan $(n=200)$} & \multicolumn{2}{|c|}{ USA ( $n=173)$} \\
\hline & & Mean(SD) & Impact Rating & Mean(SD) & Impact Rating & Mean(SD) & Impact Rating \\
\hline Section 1 & $\begin{array}{c}\text { General } \\
\text { information }\end{array}$ & $2.50(0.51)$ & Moderate & $2.86(0.56)$ & Moderate & $2.67(0.69)$ & Moderate \\
\hline Section 2 & $\begin{array}{l}\text { Reaction to } \\
\text { stuttering }\end{array}$ & $2.65(0.69)$ & Moderate & $2.97(0.68)$ & Moderate & $2.75(0.81)$ & Moderate \\
\hline Section 3 & $\begin{array}{l}\text { Communication } \\
\text { in daily situation }\end{array}$ & $2.44(0.80)$ & Moderate & $2.57(0.72)$ & Moderate & $2.66(0.77)$ & Moderate \\
\hline Section 4 & Quality of life & $2.61(0.94)$ & Moderate & $2.74(0.81)$ & Moderate & $2.37(0.87)$ & Moderate \\
\hline & Total & $2.56(0.67)$ & Moderate & $2.79(0.63)$ & Moderate & $2.60(0.73)$ & Moderate \\
\hline
\end{tabular}

Iranian Rehabilitation Journal

\section{Discussion}

The current study investigated the validity and reliability of the final form of the OASES-A-P. It is called "the final" because in a previous preliminary study, Shafie et al. investigated the validity and the reliability of the Persian translated form [29]. We made minor revisions to the resulted form and completed the validation procedure along with the calculation of impact scores and impact ratings. Translation quality, face validity, and

Table 3. The impact scores and impact ratings of four separate sections of the OASES-A-P

\begin{tabular}{|c|c|c|c|}
\hline & Section & Mean(SD) & Impact Rating \\
\hline Section $1 \mathrm{~A}$ & General information about your speech & $2.60(0.64)$ & Moderate \\
\hline Section $1 \mathrm{~B}$ & How knowledgeable are you about ...? & $2.29(0.71)$ & Moderate \\
\hline Section $1 \mathrm{C}$ & Overall how do you feel about ...? & $2.47(0.58)$ & Moderate \\
\hline Section $2 \mathrm{~A}$ & When you think about your stuttering, how often do you feel ...? & $2.51(0.84)$ & Moderate \\
\hline Section 2 B & How often do you ...? & $2.59(0.75)$ & Moderate \\
\hline Section $2 \mathrm{C}$ & To what extent do you agree or disagree with the following statements? & $2.77(0.74)$ & Moderate \\
\hline Section $3 \mathrm{~A}$ & $\begin{array}{l}\text { How difficult is it for you to communicate in following general situa- } \\
\text { tions? }\end{array}$ & $2.52(0.83)$ & Moderate \\
\hline Section 3 B: & $\begin{array}{l}\text { How difficult is it for you to communicate in following situations at } \\
\text { work? }\end{array}$ & $2.58(1.10)$ & Moderate \\
\hline Section $3 \mathrm{C}$ & How difficult is it for you to communicate in following social situations? & $2.48(0.86)$ & Moderate \\
\hline Section $3 \mathrm{D}$ & $\begin{array}{l}\text { How difficult is it for you to communicate in following situations at } \\
\text { home? }\end{array}$ & $1.74(0.66)$ & Mild-to-moderate \\
\hline Section $4 \mathrm{~A}$ & How much is your overall quality of life negatively affected by ...? & $2.97(1.06)$ & Moderate \\
\hline Section 4 B & $\begin{array}{l}\text { Overall, how much does stuttering interfere with your satisfaction with } \\
\text { communication ...? }\end{array}$ & $2.53(0.97)$ & Moderate \\
\hline Section $4 \mathrm{C}$ & Overall, how much does stuttering interfere with your ...? & $2.23(0.92)$ & Mild-to-moderate \\
\hline Section $4 \mathrm{D}$ & Overall, how much does stuttering interfere with your ...? & $2.72(1.17)$ & Moderate \\
\hline Section $4 \mathrm{E}$ & Overall, how much does stuttering interfere with your ...? & $2.48(1.07)$ & Moderate \\
\hline
\end{tabular}


content validity were examined first. All were shown to be acceptable.

The revised tool then underwent internal consistency analysis, test-retest reliability analysis, and item analysis. The results proved the adequacy of the questionnaire for Persian-speaking adults who stutter.

The mean score of all items ranged from 1.45 to 3.78 , with standard deviations ranging from 0.72 to 1.44 . These results are similar to the findings from studies of the OASES in the USA [18] and Japan [24]. Consistent with prior results, no ceiling effect was found [24]. This may be explained as the OASES was designed to cover the wide range of the impact that different speakers may experience as a result of stuttering. Yet, 6 items of the OASESA-P did not receive a " 5 " from any participants, suggesting that for this sample of Persian speakers, at least, none experienced the most extreme adverse impact on these specific aspects of stuttering. In the Japanese version of the OASES-A, 2 items did not result in a score of "5." The Japanese version showed floor effect just for 5 items while the Dutch version showed floor effects for 30 items [22]. This study revealed floor effects for 10 items.

As was evident from Table 1, the impact of sections in a high to low order for Iranian adults were section 2 (reactions to stuttering), section 4 (quality of life), section 1 (general information), and section 3 (communication in daily situations). The reactions to stuttering also obtained the highest impact score in Australian and USA and Japanese studies. In the Dutch study, it was the second in the order, and the first component was the general information.

Table 2 revealed that the least impact owes to communication in daily situation for Iran and Japan, and QOL for USA, Australia and Dutch. However, the whole pattern, mean scores SDs, and impact ratings seem similar for the countries. The section of reactions to stuttering which proved to have a high impact tries to explore the individual's own reactions to stuttering. The finding which deserves attention is that like Japan, USA, Australia and Holland, the total impact rating was moderate for Iran.

As is revealed by Table 3, section $4 \mathrm{~A}$ (how much is your overall quality of life negatively affected by ...?) revealed the highest impact score, and section $3 \mathrm{D}$ (how difficult is it for you to communicate in following situations at home?) earned the lowest impact score. All the subsections showed a moderate impact except Section 3 $\mathrm{D}$ (how difficult is it for you to communicate in following situations at home?) and Section $4 \mathrm{C}$ (overall, how much does stuttering interfere with your ...?), which had mild-to-moderate impact ratings.

The finding that section $3 \mathrm{D}$ (how difficult is it for you to communicate in following situations at home?) earned the lowest impact score and showed a mild-to-moderate effect on stuttering (three of the five items of this section deal with intimate relationships) may be explained by the fact that Iranian people have strong family ties. This has been previously displayed in the Global Leadership and Organizational Behavior Effectiveness (GLOBE) study in Iran [30]. The study showed that a noticeable aspect of the culture of Iranian people is devotion and unification with small clusters such as family and friends. To be an associate of a family or a fellow of a related band of friends is very worthy and significant. Family affiliates and intimate friends rely on each other for support, kindness, and help. Thus, it seems likely that Iranian adults who stutter may feel more comfortable and have an easier time communicating when at home. Again, we see that Section $3 \mathrm{D}$ (how difficult is it for you to communicate in following situations at home?) shows a mild-to-moderate effect, which confirms the GLOBE study cluster devotion mentioned in the above paragraph. The items of Section $3 \mathrm{D}$ deal with communication at home and with the family.

The finding that section $4 \mathrm{~A}$ (how much is your overall quality of life negatively affected by ...?) obtained the highest impact score is consistent with results from American, Australian, and Japanese studies. As mentioned earlier, in Iran, some studies have been done regarding QOL, communication attitude, personality characteristics and social skills of PWS [25-28]. These studies showed a relatively high impact of stuttering on the lives of PWS. As in many condition-related QOL of adults with long-lasting diseases and disorders [19], stuttering-related QOL assessment of PWS adults similarly has been the subject of investigation and clinical therapies. As Yaruss stated, OASES was developed to provide an assessment tool which is related to QOL of PWS.

However, we could not find any report or investigation in relation to reactions of Iranian people to disabilities, the resulted stigma or attitudes toward mental, physical or language disorders. This is an issue of further investigation to see how Iranian people feel about themselves being labeled as PWS.

Craig et al. (2009) studied the impact of stuttering on the QOL by means of the Medical Outcomes Study Short Form-36 (SF-36) in 200 adults who stutter [8]. In comparison to the control non-stuttering individuals, the adults who stutter were found to be significantly different on SF-36. Physical function, role-physical, pain, or gen- 
eral health disclosed no dissimilarities between groups. Nonetheless, significant differences were found for vitality, social function, emotional function, and mental health. The adults who stutter had significantly diminished QOL scores on these four parts. These results are consistent with our findings regarding the impact of stuttering on the lives of adults who stutter as revealed via OASES-A-P.

A limitation of our research was that we did not investigate the typology and severity of stuttering of our participants. Another issue concerns the time needed to complete the OASES. As was suggested by Sakai et al. (2017), shorter forms of OASES may be needed to reduce its completion time, making it easier for the users.

Stuttering as a phenomenon is perceived differently by people who experience it. Tools like OASES-A-P are useful means of assessing what these experiences are like. OASES-A-P provided by the current study will be beneficial for both Iranian SLPS who need more information than just stuttering severity to plan a comprehensive therapeutic program and for Iranian PWS who seek for a deep responsive therapy. The research seems valuable because there is yet no measure of QOL or impact of stuttering in Persian for PWS. Thus, a cross-cultural and cross-linguistic adaptation was developed, and results were compared to those from other cultural and linguistic groups [31]. Still, a need for assessment tool of the impact of stuttering on the lives of Persian-speaking children and adolescents PWS exits which would be resolved through further research. Also, it may be suggested to study the OASES-A-P in different sub-cultures of Iran.

\section{Conclusion}

As a necessary tool for examining the feelings, reactions, experiences and QOL of PWS, the OASES-A-P was translated and validated in Iran. The OASES-A-P is the Persian version of the OASES-A, which was provided through this multi-stage study and proved to be a valid and reliable instrument, applicable for the Iranian society of SLPs and adults who stutter. The results of the study will benefit the research in this field. The overall impact of stuttering for Iranian PWS proved to be moderate, and the greatest impact belonged to the reactions to stuttering section. These results might be important in the clinical settings.

\section{Ethical Considerations}

\section{Compliance with ethical guidelines}

Ethical considerations of the present research were approved by the review board of the University of Social
Welfare and Rehabilitation Sciences. Participants were informed orally regarding the study. They were free to exit the research whenever they wished. The names and demographic information were kept confidential.

\section{Funding}

This research was supported by the Deputy of Research and Technology of the University of Social Welfare and Rehabilitation Sciences.

\section{Conflict of interest}

J. Scott Yaruss and Robert W. Quesal are co-authors of the original OASES in English and receive royalties for its sale. J. Scott Yaruss is also co-owner of the publishing company for the OASES, Stuttering Therapy Resources.

\section{Acknowledgements}

The authors wish to appreciate the Iranian PWS for their intimate cooperation with the research project.

\section{References}

[1] Corcoran JA, Stewart M. Stories of stuttering: A qualitative analysis of interview narratives. Journal of Fluency Disorders. 1998; 23(4):247-64. [DOI:10.1016/S0094-730X(98)00020-5]

[2] Crichton-Smith I. Communicating in the real world: Accounts from people who stammer. Journal of Fluency Disorders. 2002;27(4):333-52. [DOI:10.1016/S0094-730X(02)00161-4]

[3] Alm PA. Stuttering in relation to anxiety, temperament, and personality: Review and analysis with focus on causality. Journal of Fluency Disorders. 2014; 40:5-21. [DOI:10.1016/j. jfludis.2014.01.004] [PMID]

[4] Iverach L, Rapee RM. Social anxiety disorder and stuttering: Current status and future directions. Journal of Fluency Disorders. 2014; 40:69-82. [DOI:10.1016/j.jfludis.2013.08.003] [PMID]

[5] Iverach L, Menzies RG, O'Brian S, Packman A, Onslow M. Anxiety and stuttering: Continuing to explore a complex relationship. American Journal of Speech-Language Pathology. 2011; 20(3):221-32.[DOI:10.1044/1058-0360(2011/10-0091)]

[6] Iverach L, O'Brian S, Jones M, Block S, Lincoln M, Harrison E, et al. Prevalence of anxiety disorders among adults seeking speech therapy for stuttering. Journal of Anxiety Disorders. 2009; 23(7):928-34. [DOI:10.1016/j.janxdis.2009.06.003] [PMID]

[7] Bricker Katz G, Lincoln M, Cumming S. Stuttering and work life: An interpretative phenomenological analysis. Journal of Fluency Disorders. 2013; 38(4):342-55. [DOI:10.1016/j. jfludis.2013.08.001] [PMID] 
[8] Craig A, Blumgart E, Tran Y. The impact of stuttering on the quality of life in adults who stutter. Journal of Fluency Disorders. 2009; 34(2):61-71. [DOI:10.1016/j.jfludis.2009.05.002] [PMID]

[9] Brutten GJ, Dunham SL. The communication attitude test: A normative study of grade school children. Journal of Fluency Disorders. 1989; 14(5):371-7. [DOI:10.1016/0094730X(89)90017-X]

[10] Luc F, Brutten GJ. Speech-associated attitudes of stuttering and nonstuttering children. Journal of Speech, Language, and Hearing Research. 1991; 34(1):60-6. [DOI:10.1044/ jshr.3401.60]

[11] Guttormsen LS, Kefalianos E, Næss KA. Communication attitudes in children who stutter: A meta-analytic review. Journal of Fluency Disorders. 2015; 46:1-14. [DOI:10.1016/j. jfludis.2015.08.001] [PMID]

[12] Kasbi F, Mokhlesin M, Maddah M, Noruzi R, Monshizadeh L, Mir Mohammad Khani M. Effects of stuttering on quality of life in adults who stutter. Middle East Journal of Rehabilitation and Health. 2015; 2(1).

[13] Petersson C, Simeonsson RJ, Enskar K, Huus K. Comparing children's self-report instruments for health-related quality of life using the International Classification of Functioning, Disability and Health for Children and Youth (ICFCY). Health and Quality of Life Outcomes. 2013; 11(1):75. [DOI:10.1186/1477-7525-11-75] [PMID] [PMCID]

[14] Hennessey NW, Dourado E, Beilby JM. Anxiety and speaking in people who stutter: An investigation using the emotional Stroop task. Journal of Fluency Disorders. 2014; 40:4457. [DOI:10.1016/j.jfludis.2013.11.001] [PMID]

[15] Messenger M, Packman A, Onslow M, Menzies R, O'Brian S. Children and adolescents who stutter: Further investigation of anxiety. Journal of Fluency Disorders. 2015; 46:15-23. [DOI:10.1016/j.jfludis.2015.07.006] [PMID]

[16] O'Brian S, Jones M, Packman A, Menzies R, Onslow M. Stuttering severity and educational attainment. Journal of Fluency Disorders. 2011; 36(2):86-92. [DOI:10.1016/j. jfludis.2011.02.006] [PMID]

[17] Van Borsel J, Brepoels M, De Coene J. Stuttering, attractiveness and romantic relationships: The perception of adolescents and young adults. Journal of Fluency Disorders. 2011; 36(1):41-50. [DOI:10.1016/j.jfludis.2011.01.002] [PMID]

[18] Yaruss JS, Quesal RW. Overall Assessment of the Speaker's Experience of Stuttering (OASES): Documenting multiple outcomes in stuttering treatment. Journal of Fluency Disorders. 2006; 31(2):90-115. [DOI:10.1016/j.jfludis.2006.02.002] [PMID]

[19] Drotar D. Measuring health-related quality of life in children and adolescents: Implications for research and practice. London: Psychology Press; 2014

[20] Yaruss JS, Quesal RW. Stuttering and the International Classification of Functioning, disability, and health (ICF): An update. Journal of Communication Disorders. 2004; 37(1):3552. [DOI:10.1016/S0021-9924(03)00052-2]

[21] Blumgart E, Tran Y, Yaruss JS, Craig A. Australian normative data for the Overall Assessment of the Speaker's Experience of Stuttering. Journal of Fluency Disorders. 2012; 37(2):83-90. [DOI:10.1016/j.jfludis.2011.12.002] [PMID]
[22] Koedoot C, Versteegh M, Yaruss JS. Psychometric evaluation of the Dutch translation of the Overall Assessment of the Speaker's Experience of Stuttering for adults (OASES-AD). Journal of Fluency Disorders. 2011; 36(3):222-30. [DOI:10.1016/j.jfludis.2011.03.002] [PMID]

[23] Lankman RS, Yaruss JS, Franken MC. Validation and evaluation of the Dutch translation of the Overall Assessment of the Speaker's Experience of Stuttering for School-age children (OASES-SD). Journal of Fluency Disorders. 2015; 45:27-37. [DOI:10.1016/j.jfludis.2015.05.003] [PMID]

[24] Sakai N, Chu SY, Mori K, Yaruss JS. The Japanese version of the overall assessment of the speaker's experience of stuttering for adults (OASES-AJ): Translation and psychometric evaluation. Journal of Fluency Disorders. 2017; 51:50-9. [DOI:10.1016/j.jfludis.2016.11.002] [PMID]

[25] Mansuri B, Shahbodaghi MR, Tohidast SA, Kamali M. Comparing the quality of life in adults who stutter with their normal counterparts. Journal of Research in Rehabilitation Sciences. 2013; 9(2):318-27.

[26] Mohammadi H, Rezaei M, Moradi S, Barani M, Badri S, Heidari A. Comparison of quality of life in people who stutter and normal individuals. Journal of Kermanshah University of Medical Sciences. 2012; 16(6):480-6.

[27] Yazdkhasti F. [Evaluating and comparing social skills and personality characteristics in elementary school children with stuttering and their normal peers (Persian)]. Journal of Research in Rehabilitation Sciences. 2011; 7(4):533-9.

[28] Yadegari F, Darooei A, Farazi M, Alipour Heydari M [Communication attitude of stuttering and non-stuttering students (Persian)]. Thought and Behavior. 2005; 11(1):100-2.

[29] Shafiei B, Salehi A, Karimi H, Yadegari F, Sima Shirazi T, Shafiei $\mathrm{M}$. The validity and reliability of the Farsi version of "the overall assessment of the speaker's experience of stuttering-adult"(OASES-A) Questionnaire. Journal of Rehabilitation Sciences and Research. 2012; 8(1):49-56.

[30] Javidan M, Dastmalchian A. Culture and leadership in Iran: The land of individual achievers, strong family ties, and powerful elite. The Academy of Management Executive. 2003; 17(4):127-42. [DOI:10.5465/ame.2003.11851896]

[31] Guillemin F, Bombardier C, Beaton D. Cross-cultural adaptation of health-related quality of life measures: Literature review and proposed guidelines. Journal of Clinical Epidemiology. 1993; 46(12):1417-32. [DOI:10.1016/08954356(93)90142-N] 